\title{
Estimating snow water equivalent for a slightly tilted snow-covered prairie grass field by GPS interferometric reflectometry
}

\author{
Mark D Jacobson
}

\begin{abstract}
Snow water equivalent (SWE) measurements are necessary for the management of water supply and flood control systems in seasonal snow-covered regions. SWE measurements quantify the amount of water stored in snowpack; it can be estimated by the product of snow depth and density. In this paper, snow depth and density are estimated by a nonlinear least squares fitting algorithm. The inputs to this algorithm are global positioning system (GPS) signals and a simple GPS interferometric reflectometry model (GPS-IR) that incorporates a slightly tilted surface (GPS-IRT). The elevation angles of interest at the GPS receiving antenna are between $5^{\circ}$ and $30^{\circ}$. A 1-day experiment with a snow-covered prairie grass field using GPS satellites PRN 15 and PRN 18 shows potential for inferring snow water equivalent using GPS-IRT. For this case study, the average inferred snow depth $(12.4 \mathrm{~cm})$ from the two satellite tracks underestimates the in situ measurements $(17.6 \mathrm{~cm} \pm 1.5 \mathrm{~cm})$. However, the average inferred snow density $\left(0.085 \mathrm{~g} \cdot \mathrm{cm}^{-3}\right)$ from the two satellite tracks is within the in situ measurement range $\left(0.08 \mathrm{~g} \cdot \mathrm{cm}^{-3} \pm 0.02 \mathrm{~g} \cdot \mathrm{cm}^{-3}\right)$. Consequently, the average inferred SWE $\left(1.05 \mathrm{~g} \cdot \mathrm{cm}^{-2}\right)$ from the two satellite tracks is within the in situ calculation range $\left(1.40 \mathrm{~g} \cdot \mathrm{cm}^{-2} \pm 0.36 \mathrm{~g} \cdot \mathrm{cm}^{-2}\right)$. These results are also compared with the GPS-IR model.
\end{abstract}

Keywords: Global positioning system (GPS); Snow depth; Snow density; Snow water equivalent (SWE); Multipath; Reflection

\section{Introduction}

The amount of water stored in snowpack is one of the most important measurements for the management of water supply and flood control systems in seasonal snowcovered regions. Snow water equivalent (SWE) represents the amount of water stored in snowpack. Snow is important in agriculture for the northern Great Plains in the USA and the Canadian Prairies. For example, during the winter season, snow cover protects crops from extreme cold temperatures. In addition, snow provides moisture for these crops when the snow melts into the soil [1-3]. Improved winter-time snow measurements, such as SWE, would help resource managers to improve water use efficiencies in these areas. In particular, the spatial nature of SWE would give watershed researchers a new tool to use in scaling and in extrapolating point measurements to areas. Currently, SWE data are from point measurements.

Correspondence: mjacobson@msubillings.edu

Department of Mathematics, Montana State University Billings, Billings, MT 59101, USA
The United States Natural Resources Conservation Service (NRCS) of the Department of Agriculture (USDA) is dedicated in supporting Western US water managers in developing new techniques and products to improve water use efficiencies wherever possible.

In the mountainous Western United States, including Alaska, snow depth and SWE measurements are performed by the National Water and Climate Center (NWCC) USDA NRCS. They operate and manage the snowpack telemetry (SNOTEL) system [4-6] in highelevation areas. This system has provided critical snow data for approximately 30 years. Currently, this network operates 730 remote sites. Although this method has a higher temporal resolution, it misses critical spatial variability because of its limited spatial footprints. In order to increase the spatial coverage of snow depth and SWE in these regions, a promising new remote-sensing technique using the reflected signals of the global navigation satellite systems (GNSS) is being investigated [7-11]. Such a remote-sensing technique is commonly termed GNSS

\section{黑 Springer}


reflectometry (GNSS-R). Specifically, it has been reported that reflected global positioning system (GPS) signals can provide useful information about snow depth [12-16] and possibly SWE $[17,18]$. From recent snow depth studies [14], this promising new technique has been given the name GPS interferometric reflectometry (GPS-IR). This method is basically an L-band ground-based interferometer. In other words, a GPS receiver collects both direct and reflected GPS signals simultaneously which produces a resulting interference pattern. By processing and analyzing this pattern, the characteristics of the reflection surface can be derived, and the related geophysical parameters, such as snow depth and density, can be inferred. This paper outlines a technique for estimating dry snow depth, density, and SWE (the product of snow depth and density) for a slightly tilted snow-covered prairie grass field. For this paper, the name GPS-IR signifies using the GPS-IR technique with a horizontal ground surface (zero ground tilt) [17]. Consequently, the name GPS-IRT signifies using the GPS-IR technique with a tilted ground surface (nonzero ground tilt) along the axis of the receiving antenna's main beam center. In situ snow depth and density measurements are compared with the inferred GPS-IRT and GPS-IR results. The resulting SWE results are also compared.

\section{Model}

The simple model described by Jacobson [17] is used to infer snow depth and density. This model is now modified to include flat snow and prairie grass layers of infinite extent above a slightly tilted, flat frozen-soil surface of infinite extent. As before, the model includes a vertically mounted, hemispherical directional, and right-hand circularly polarized (RHCP) GPS receiving antenna with no sidelobes and with uniform plane waves with a monochromatic frequency. Figure 1 illustrates the total field (the sum of the direct and specularly reflected signals) at the GPS receiving antenna in the local (primed coordinates shown in red) and reference (unprimed coordinates shown in black) frames; the tilt angle $\left(\theta_{\mathrm{t}}\right)$ is along the axis of the receiving antenna's main beam center, and the $X^{\prime}$ axis represents the tilted air-snow interface. From Figure 1, the angular relationship between the local and reference frames is given by

$$
\theta^{\prime}=\theta+\theta_{\mathrm{t}}
$$

where $\theta$ is the elevation angle (degrees) in the reference frame, $\theta_{\mathrm{t}}$ is the tilt angle (degrees), and $\theta^{\prime}$ is the elevation angle (degrees) in the local frame.

The total received signal power levels in both simulation and measurement results have been normalized to maximum signal levels for each satellite track. This normalization is referred to as the relative received

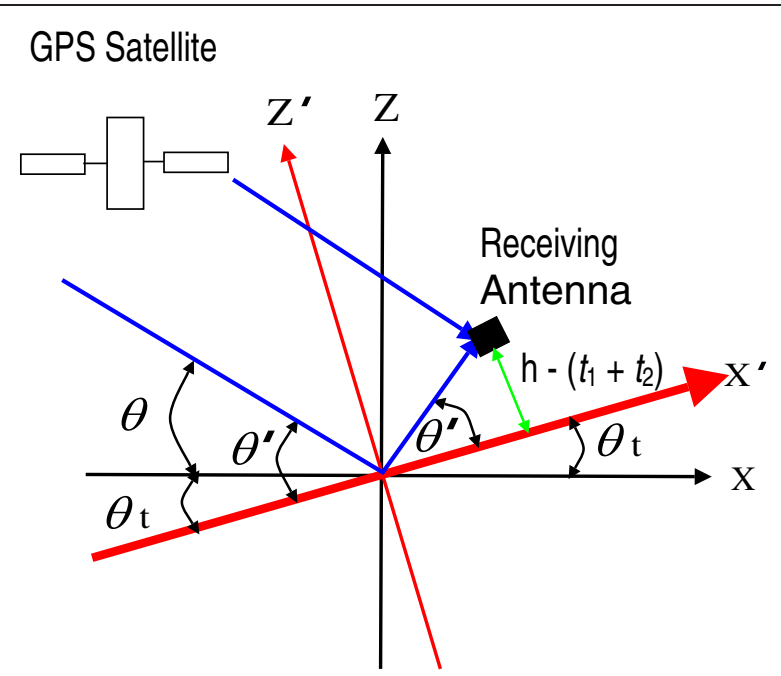

Figure 1 Geometry of the local (primed coordinates) and reference (unprimed coordinates) frames. The elevation angle in the reference frame is given by $\theta$. The tilt angle $\left(\theta_{t}\right)$ at the air-snow interface ( $X^{\prime}$ axis) is along the axis of the receiving antenna's main beam center. The elevation angle in the local frame is given by $\theta^{\prime}$. The receiving antenna's height above the tilted air-snow interface (shown in green) is given by $h-\left(t_{1}+t_{2}\right)$, where $h$ is the height of antenna above the frozen-soil surface $(m), t_{1}$ is the snow layer thickness $(m)$, and $t_{2}$ is the prairie grass layer thickness $(m)$ as given in [17].

power. Reflected signals from the air-snow interface arrive at the GPS receiver both coherently and incoherently. The proportions of these signals depend upon on the roughness of the air-snow surface. Smooth surfaces produce specular reflection signals which occur primarily within the first Fresnel zone about the specular point. This simple model neglects the scattering from rough surfaces and the incoherent component of the simulated received reflected power. Conversely, the measured received signal power at the GPS receiver includes these factors. A 1-day experiment attempts to partially answer the following question: Can this simple model be used to estimate snow depth and density for a slightly tilted snow-covered prairie grass field?

The modelled relative power at the vertically mounted, RHCP GPS receiving antenna is given in [17] with the modification that $\theta$ in [17] is replaced with $\theta^{\prime}$ which is given in (1). The relative power expression is given by two terms. The first term is the normalized direct coefficient for the RHCP field component. The second term is the reflected coefficient for the RHCP field component from the combination of the snow layer, the prairie grass layer, and the frozen soil with the appropriate phase shift. For calculation purposes, the reflected coefficient for the RHCP field component is represented as the difference between the reflected coefficients for the 
horizontally and vertically polarized fields [19]. With this in mind, the received relative power is

$$
P=\left|1+\frac{\left(r_{\mathrm{h}}-r_{\mathrm{v}}\right)}{2} \exp (i \phi)\right|^{2},
$$

where 1 is the normalized direct coefficient for the RHCP field component, $r_{\mathrm{h}}$ is the reflection coefficient for the horizontally polarized field component; $r_{\mathrm{v}}$ is the reflection coefficient for the vertically polarized field component; $\phi=\frac{4 \pi\left[h+t_{3}-\left(t_{1}+t_{2}\right)\right] \sin \theta}{\lambda_{0}}$ is the phase shift difference in physical path length between the direct path and the air-snow interface reflected path [20]; $i=\sqrt{-1} ; h$ is the height of antenna above the frozen-soil surface $(\mathrm{m}) ; t_{1}$ is the snow layer thickness $(\mathrm{m}) ; t_{2}$ is the effective prairie grass layer thickness $(\mathrm{m}) ; t_{3}$ is the frozen-soil penetration depth $(\mathrm{m})$, i.e., the effective reflector depth; $\theta^{\prime}$ is the local elevation angle (degrees) as given in (1); $c=2.997925 \times 10^{8} \mathrm{~m} / \mathrm{s}$ is the speed of light in a vacuum; $f=1.57542 \mathrm{GHz}$ is the GPS L1 frequency; and $\lambda_{0}=c / f=0.1902937 \mathrm{~m}$ is the GPS L1 free-space wavelength.

The three parameters embedded in (2) are the relative complex permittivity values of dry snow $\left(\varepsilon_{1}\right)$, crested wheatgrass $\left(\varepsilon_{2}\right)$, and frozen soil $\left(\varepsilon_{3}\right)$. The dry snow parameter $\left(\varepsilon_{1}\right)$ is a function of the relative density of dry snow $\left(\rho_{\mathrm{d}}\right.$ in $\left.\mathrm{g} \mathrm{cm}^{-3}\right)$, the temperature of snow $\left(T\right.$ in $\left.{ }^{\circ} \mathrm{C}\right)$, and the frequency $(f$ in $\mathrm{Hz})$. The fixed input parameters of the model are given in [17] and are repeated in Table 1; the imaginary parts of $\varepsilon_{2}$ and $\varepsilon_{3}$ are neglected because of the small amount of moisture content in crested wheatgrass and frozen soil for the environmental conditions in the experiment. These fixed parameters provided a reasonable fit between theory and measurement as shown in the next section. In future studies, an analysis will be done to determine the effect of varying these parameters in inferring snow depth and density.

The input parameters are relative complex permittivity value of crested wheatgrass $\left(\varepsilon_{2}\right)$, the relative complex permittivity value of frozen soil $\left(\varepsilon_{3}\right)$, the prairie grass layer thickness $\left(t_{2}\right)$, the frozen-soil penetration depth $\left(t_{3}\right)$, and the height of the antenna above the frozen-soil surface $(h)$.

It must be noted that the 5 -cm frozen-soil penetration depth is obtained from dry-ground assumptions [14,21,22]. This penetration depth is more likely deeper for frozen ground. Furthermore, soil penetration depth is still unknown for active systems like GPS-IR; however, it known for passive systems $[23,24]$. Therefore, $5 \mathrm{~cm}$ is only an

\section{Table 1 Fixed input parameters for the model}

\begin{tabular}{lcccc}
\hline $\boldsymbol{\varepsilon}_{\mathbf{2}}$ & $\boldsymbol{\varepsilon}_{\mathbf{3}}$ & $\boldsymbol{t}_{\mathbf{2}}(\mathbf{c m})$ & $\boldsymbol{t}_{\mathbf{3}}(\mathbf{c m})$ & $\boldsymbol{h}(\mathbf{c m})$ \\
\hline $1.5-i 0$ & $4.4-i 0$ & 5.3 & 5.0 & 71.5 \\
\hline
\end{tabular}

estimate for the penetration depth of frozen ground when using GPS signals.

The inferred tilt angles, along the axis of the receiving antenna's main beam center, are fixed at

$$
\begin{array}{ll}
\theta_{\mathrm{t}}=-1.7 & \text { for GPS PRN 15 } \\
\theta_{\mathrm{t}}=-1.6 & \text { for GPS PRN 18 }
\end{array}
$$

These inferred tilt angles provide the optimal fit between theory and measurement (see the next section). Furthermore, a small negative tilt (terrain is sloping downhill towards the axis of the receiving antenna's main beam center) was observed at the measurement site. The small tilt angle difference between the two GPS satellites occurs because the satellites' azimuth angle tracks are not along the axis of the receiving antenna's main beam (see the next section). In other words, the reflected GPS signals from each satellite are from different sections of the snow-covered prairie grass field which, in turn, have slightly different slopes.

\section{SWE estimation}

A Trimble Lassen LP GPS L1 (1.57542 GHz; Sunnyvale, CA, USA) receiver was used to test the theory's potential for inferring snow depth and density from a snow-covered prairie grass field. Figure 2 is a photograph (taken on January 20, 2012) of the snow-covered prairie grass field used in this experiment; the site is located $13 \mathrm{~km}$ west of Billings, MT, USA. The axis of the receiving antenna's main beam center was located at an azimuth angle of $110^{\circ}$. The site was located in a terrain that minimized blockage and shadowing which help increase the amount of specular reflection from the smooth snow surface. A hemispherical directional, RHCP antenna was mounted vertically with a $15 \mathrm{~cm} \times 15-\mathrm{cm}$ metal square plate on a tripod in order to receive the direct and snow-reflected signals with equal gain. The antenna height $(h)$ was approximately $71.5 \mathrm{~cm}$ above the frozen-soil surface. This translates to an antenna height of approximately $48.6 \mathrm{~cm}$ above the air-snow interface. This height was restricted by the vertical adjustment mechanism of the tripod. The active Trimble antenna $(50.5 \mathrm{~mm} \times 42.0 \mathrm{~mm} \times 13.8 \mathrm{~mm})$ consists of a microstrip patch antenna, a preamplifier, a radome, and a ground plane. See Table 2 for the GPS antenna specifications. The preamplifier circuit amplifies the noise-like GPS spread spectrum signal. The receiver is a standard closed loop type. Power levels were directly recorded in decibels $(\mathrm{dB})$ from the GPS receiver every $0.5 \mathrm{~s}$ to a laptop computer.

For multipath studies, it is helpful to plot the nominal specular reflection point on the local horizontal plane surrounding the antenna [12]. This emphasizes the directions of the tracks as they will appear on the ground and gives some intuition about the spatial extent of the 


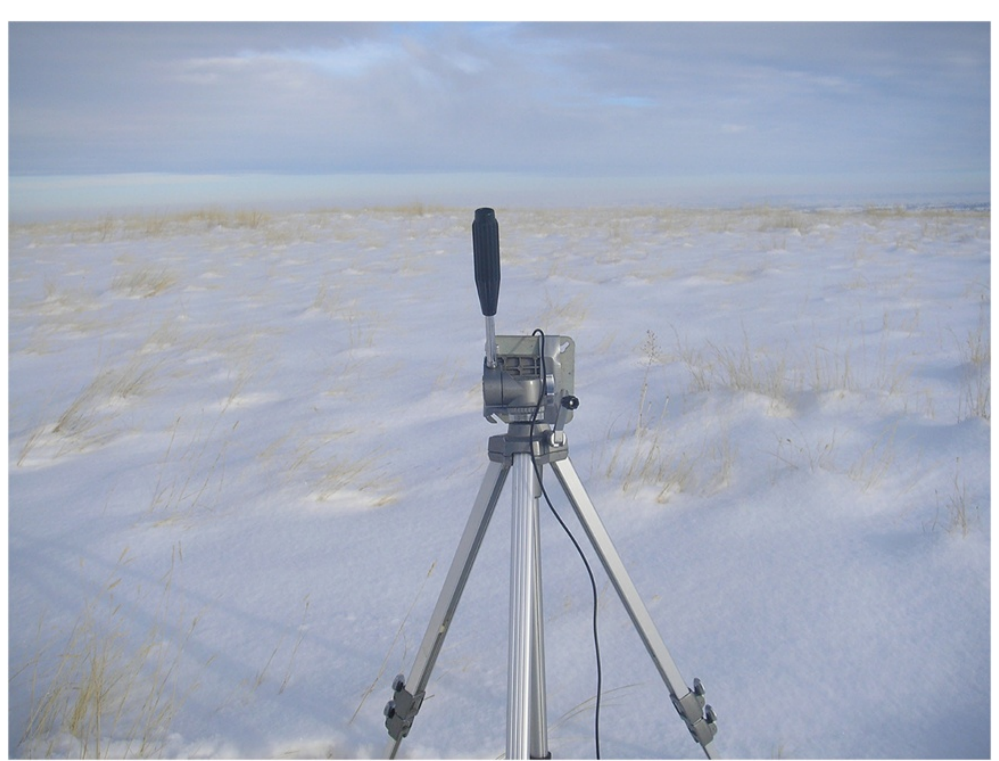

Figure 2 Snow-covered crested wheatgrass field. The antenna is mounted vertically on the tripod with $h=71.5 \mathrm{~cm}$. This photograph was taken on January 20, 2012 near Billings, MT, USA.

method. The radial distance of the reflection point is the antenna height above the air-snow interface divided by the tangent of the elevation angle. The azimuth angle is from the respective GPS satellite. Figure 3 shows the reflection points for satellites PRN 15 and PRN 18 for elevations below $30^{\circ}$. These satellites were chosen among the available GPS satellites of the constellation because their azimuth angle tracks were close to the axis of the receiving antenna's main beam center of $110^{\circ}$.

The measured data from the snow-covered prairie grass field are fitted with (2) in a quasi-Newton algorithm (QNA) [25,26]. The measurements were performed on January 20, 2012 with partly cloudy skies between 20:33 and 21:38 GPS time for satellite PRN 15 and between 22:20 and 23:30 GPS time for satellite PRN 18. The azimuth angles were at approximately $51^{\circ}$ for PRN 15 for the 1.1-h measurement. On the other hand, the azimuth angles increased from $80^{\circ}$ to $100^{\circ}$ for PRN 18 for the 1.2-h measurement. Fresh snow was deposited on the prairie

Table 2 Specifications for GPS receiving antenna

\begin{tabular}{ll}
\hline Specification & \multicolumn{1}{c}{ Value } \\
\hline Frequency range & $1,575.42 \pm 1.023 \mathrm{MHz}$ \\
Gain & $+3.0 \mathrm{dBi}$, minimum at $90^{\circ}$ \\
& $-4.0 \mathrm{dBi}$, minimum at $20^{\circ}$ \\
Polarization & $\mathrm{RHCP}$ \\
Axial ratio & $+4.0 \mathrm{~dB}$, maximum at $90^{\circ}$ \\
& $+6.0 \mathrm{~dB}$, maximum at $10^{\circ}$ \\
Half-power beamwidth & $140^{\circ}$ \\
Front-to-back ratio & $+15 \mathrm{~dB}$ \\
\hline
\end{tabular}

grass field from a 2-day storm that occurred from January 18 to 19,2012 . The snow storm was preceded by cold air temperatures of approximately $-20^{\circ} \mathrm{C}$. This produced very low snow density values $[14,24]$.

The techniques for measuring snow depth $\left(t_{1}\right)$ and snow density $\left(\rho_{\mathrm{d}}\right)$ are given in [17]. Briefly, snow depths

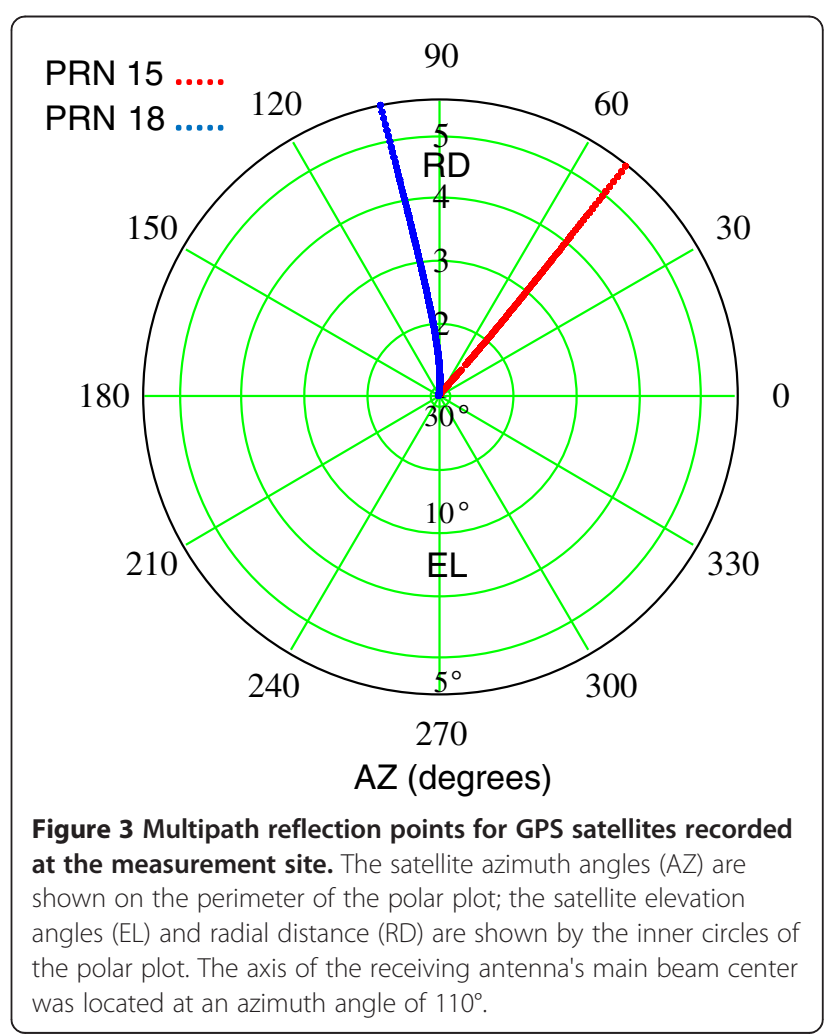


$\left(t_{1}\right)$ were measured with a metal ruler. $\rho_{\mathrm{d}}$ measurements required the following tools: (1) a 60-cm-long polyvinyl chloride (PVC) tube with a 7.6- $\mathrm{cm}$ inside diameter (one end of this tube was beveled to enhance the cutting affect through the snow), (2) a 5-cm-thick circular Styrofoam (The Dow Chemical Company, Midland, MI, USA) with a $25-\mathrm{cm}$ diameter, (3) a portable digital scale with a resolution of $0.1 \mathrm{~g}$ and an accuracy of $0.5 \mathrm{~g}$, (4) a 4-L plastic ziplock bag, and (5) a rigid sheet of cardboard. The average snow temperatures for the PRN 15 and PRN 18 tracks were $-9.5^{\circ} \mathrm{C}$ and $-5.8^{\circ} \mathrm{C}$, respectively. The snow temperatures were measured with a digital thermometer with an attached probe with a resolution of $0.1^{\circ} \mathrm{C}$ and an accuracy of $1^{\circ} \mathrm{C}$. This probe was placed at approximately $1 \mathrm{~cm}$ below the air-snow interface at the site location. This is a one-point temperature measurement over time. Eleven pairs of snow depth and density were taken during this experiment.

The measured snow depth and density ranges are approximately $17.6 \mathrm{~cm} \pm 1.5 \mathrm{~cm}$ and $0.08 \mathrm{~g} \cdot \mathrm{cm}^{-3} \pm 0.02 \mathrm{~g} \cdot \mathrm{cm}^{-3}$, respectively; the calculated SWE range is approximately $1.40 \mathrm{~g} \cdot \mathrm{cm}^{-2} \pm 0.36 \mathrm{~g} \cdot \mathrm{cm}^{-2}$ [17]. For this paper, the elevation angles were restricted to be between $5^{\circ}$ and $30^{\circ}$ in order to maximize the multipath effects from the snow layer. This occurs because the electrical path length of the GPS signal through the snow increases as the elevation angle decreases. This elevation range is approximately less than the Brewster angle ( $\geq 29^{\circ}$ [27]) for the snow-covered prairie grass field. Therefore, the reflected wave is not purely RHCP but is right-hand elliptically polarized (RHEP) [19]. For this elevation angle range (similar to that chosen by [12,14-18]), there are 7,292 data points for PRN 15 and 8,097 data points for PRN 18. Satellite PRN 15 had fewer data points than PRN 18 because the GPS receiver stopped receiving data from PRN 15 between elevation angles of $19.2^{\circ}$ and $18.1^{\circ}$. This occurred because the portable generator ran out of gas. Fortunately, these missing data points did not seriously affect this study.

We use the geometric optics approximation (far field, Fraunhofer diffraction) to estimate the first Fresnel zone dimensions. The first Fresnel zone dimensions are used to determine if the receiving antenna's power pattern, relative to the specularly reflected path, is within the area of the snow-covered prairie grass field. With an antenna height of $48.6 \mathrm{~cm}$ above the air-snow interface and an elevation angle of $5^{\circ}$, the first Fresnel zone is calculated to have a major axis length of approximately $26 \mathrm{~m}$ and a minor axis length of approximately $2.3 \mathrm{~m}$
[10]. The size of this ellipse is largest here at $5^{\circ}$ and becomes smaller and closer to the antenna as the satellite rises. For example, the entire first Fresnel zone is only a few meters from the antenna when the elevation angle is at $30^{\circ}$. The snow-covered prairie grass field is approximately topographically flat for approximately $60 \mathrm{~m}$ in the direction of the axis of the receiving antenna's main beam (major axis) and also for approximately $100 \mathrm{~m}$ in the direction perpendicular (minor axis) to the axis of the receiving antenna's main beam. However, there is a small negative ground surface slope (tilt $<5^{\circ}$ ) with respect to the horizontal when approaching the receiving antenna along its major axis; this small negative slope was neglected in [17]. Therefore, the first Fresnel zone lies entirely on a slightly tilted snow-covered prairie grass field.

In order to utilize a QNA efficiently in finding estimates of snow depth and density, we use the following logarithmic normalization given in [17]:

$$
P d B=10 \log \left(\frac{P}{\text { Norm }}\right)
$$

where $P$ is given in (2), and Norm is the normalization constant that minimizes the difference, in a least squares sense between theory and measurement. In this case study, the initial guess value of Norm is set to 2.5 in the QNA for each paired combination of snow depth and density. The resulting Norm value produced by the QNA for each paired combination is between 2.0 and 3.0. Each final Norm value minimizes the errors in the constraints [26]. Essentially, the Norm value vertically shifts the theoretical curve to match the measurement data in a least squares sense. The normalization constant, Norm, is used as the input to the fitting function $P d B$ in a QNA. A snow depth range of approximately 10 to $15 \mathrm{~cm}$ and a snow density range from 0.04 to 0.12 $\mathrm{g} \cdot \mathrm{cm}^{-3}$ are chosen to bracket the measured values of this experiment. For each GPS satellite, 112 different paired combinations of snow depth and density provided the necessary resolution and range to estimate the absolute minimum between theory and measurement using a QNA.

Each pair of snow depth and density value is used as an input to a QNA. The output of a QNA produces a standard error (SE) by performing a nonlinear least squares fit between theory and measurement. The process for calculating the SE for each output pair of QNA is given by the following expression [17]:

$$
\mathrm{SE}(N o r m)=\min \left\{\sqrt{\left.\frac{1}{n-2} \sum_{i=1}^{i=n}\left[y\left(\theta_{i}\right)-P d B\left(\theta_{i}, \theta_{\mathrm{t}}, \text { Norm }, t_{1}, t_{2}, t_{3}, \rho_{\mathrm{d}}, \varepsilon_{2}, \varepsilon_{3}, T, f\right)\right]^{2}\right\}}\right.
$$


where $y$ is the relative measured power value in $\mathrm{dB}$; $P d B$ is the normalized fitting function in $\mathrm{dB} ; \theta_{i}$ are the elevation angles in degrees; $\theta_{\mathrm{t}}, t_{1}, t_{2}, t_{3}, \rho_{\mathrm{d}}, \varepsilon_{2}, \varepsilon_{3}$, $T$, and $f$ are the parameters given in Section $2 ; n$ is the number of data points for each satellite track, and min is the abbreviation for minimize.

This procedure is performed for all 112 different paired combinations for both PRN 15 and PRN 18. The best estimates of snow depth and density are determined by which QNA output that produces the smallest SE. Figure 4 shows a two-dimensional contour plot of the QNA output SE values produced by the 112 input pairs for PRN 15. A snow depth of $13.0 \mathrm{~cm}$ and a snow density of $0.08 \mathrm{~g} \cdot \mathrm{cm}^{-3}$ produce the smallest $\mathrm{SE}$ of $0.377 \mathrm{~dB}$; the resulting $\mathrm{SWE}=$ $1.04 \mathrm{~g} \cdot \mathrm{cm}^{-2}=10.4 \mathrm{~kg} \cdot \mathrm{m}^{-2}$. Figure 5 shows a twodimensional contour plot of the QNA output SE values produced by the 112 input pairs for PRN 18 . A snow depth of $11.7 \mathrm{~cm}$ and a snow density of 0.09 $\mathrm{g} \cdot \mathrm{cm}^{-3}$ produce the smallest $\mathrm{SE}$ of $0.760 \mathrm{~dB}$; the resulting $\mathrm{SWE}=1.05 \mathrm{~g} \cdot \mathrm{cm}^{-2}=10.5 \mathrm{~kg} \cdot \mathrm{m}^{-2}$. The arithmetical average (AVG) values for these results obtained for PRN 15 and PRN 18 produce a snow depth of $12.4 \mathrm{~cm}$ and a snow density of $0.085 \mathrm{~g} \cdot \mathrm{cm}^{-3}$; the resulting $\mathrm{SWE}=1.05 \mathrm{~g} \cdot \mathrm{cm}^{-2}=10.5 \mathrm{~kg} \cdot \mathrm{m}^{-2}$.

The measurements and the theoretical results for PRN 15 and PRN 18 are shown in Figures 6 and 7,

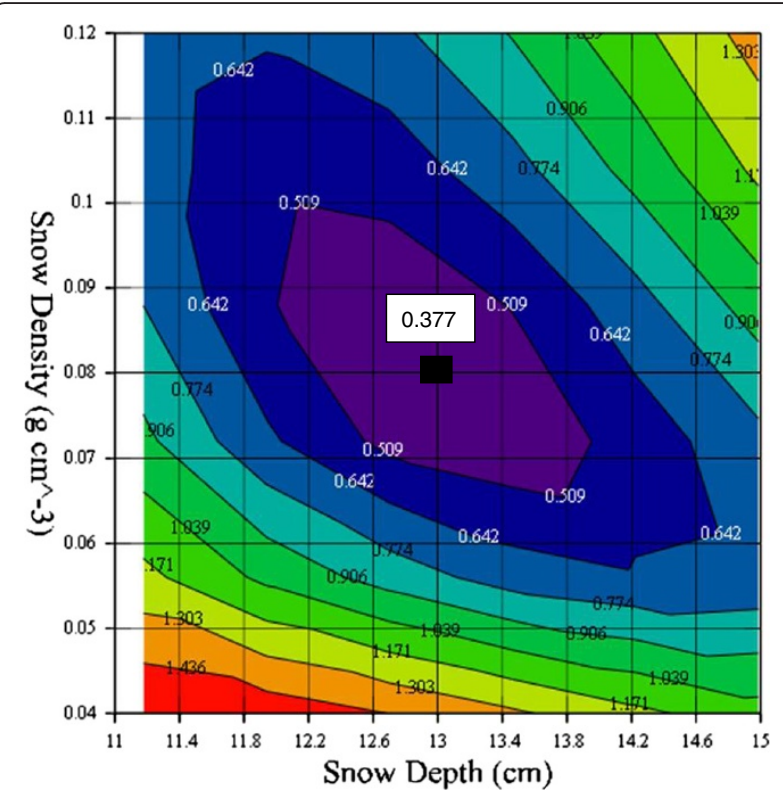

Figure 4 Two-dimensional contour plot of snow depth $\left(t_{1}\right)$ and snow density $\left(\rho_{\mathrm{d}}\right)$ for PRN 15. The plot has contour values of the SE of the QNA output values produced by the 112 input pair combinations of snow depth and density using a QNA. The minimum SE value of $0.377 \mathrm{~dB}$ (black square) is produced by a 13.0-cm-thick snow layer with a snow density of $0.08 \mathrm{~g} \cdot \mathrm{cm}^{-3}\left(S W E=1.04 \mathrm{~g} \mathrm{~cm}^{-2}\right.$ ).

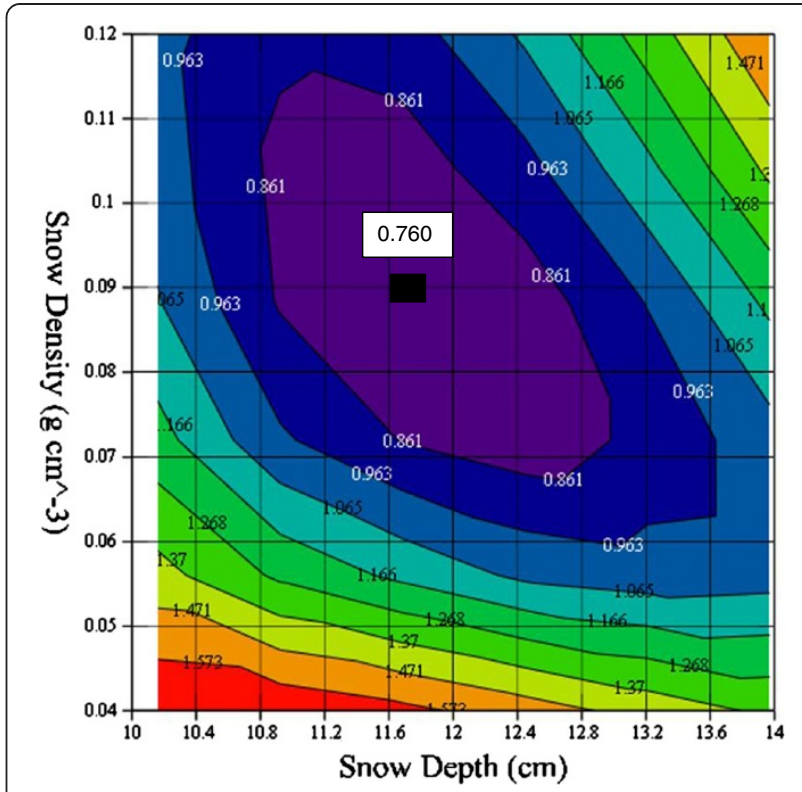

Figure 5 Two-dimensional contour plot of snow depth $\left(t_{1}\right)$ and snow density $\left(\rho_{\mathrm{d}}\right)$ for PRN 18. The plot has contour values of the SE of the QNA output values produced by the 112 input pair combinations of snow depth and density using a QNA. The minimum SE value of $0.760 \mathrm{~dB}$ (black square) is produced by an 11.7-cm-thick snow layer with a snow density of $0.09 \mathrm{~g} \cdot \mathrm{cm}^{-3}\left(S W E=1.05 \mathrm{~g} \mathrm{~cm}^{-2}\right)$.

respectively. The power-level fluctuations are almost periodic with decaying exponential variation with increasing elevation angle. This is caused by the interference of the direct and specularly reflected signals. In other words, this behavior is caused by the path length difference between the direct and specularly reflected signals and the change in the complex reflection coefficient.

The inferred snow depth, snow density, and SWE values for PRN 15 and PRN 18 with their associated SE values are shown in Table 3; the GPS-IR (zero ground tilt, i.e., $\theta_{\mathrm{t}}=0^{\circ}$ ) method results and in situ range values [17] are shown for comparison. Each in situ range value consists of 11 measurements. This table shows that the inferred snow depth values from the GPS-IRT method are lower than the average in situ snow depth by approximately $5.2 \mathrm{~cm}$. This is similar to the error of 2 to $5 \mathrm{~cm}$ in snow depth retrieval relative to in situ measurements for slopes $\leq 8^{\circ}$ [12]. On the other hand, the inferred snow density values from the GPS-IRT method are within the measured snow density range. Consequently, the inferred SWE values from the GPS-IRT method are within the calculated range. For comparison purposes, the GPS-IR (zero ground tilt) method provides better estimates of snow depth than the GPS-IRT (nonzero ground tilt). 


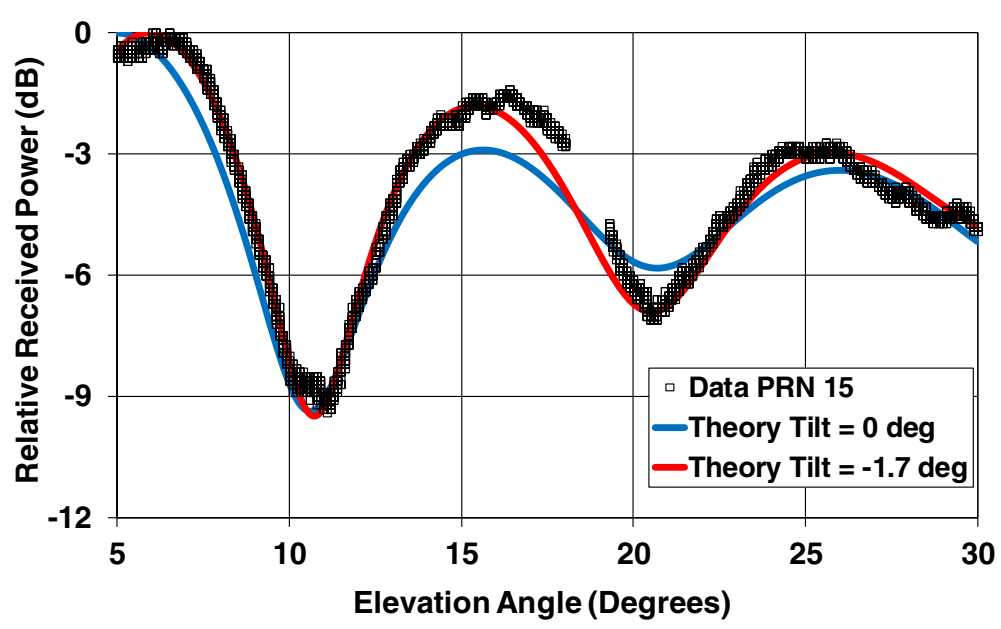

Figure 6 Theoretical (lines) and measured (squares) elevation plots for the GPS satellite PRN 15. The GPS-IRT $\left(\theta_{t}=-1.7^{\circ}\right)$ model is for a $13.0-\mathrm{cm}$-thick snow layer with a snow density of $0.08 \mathrm{~g} \cdot \mathrm{cm}^{-3}\left(S W E=1.04 \mathrm{~g} \mathrm{~cm}^{-2}\right)$. The GPS-IR $\left(\theta_{\mathrm{t}}=0^{\circ}\right)$ model is for an $18.3-\mathrm{cm}$-thick snow layer with a snow density of $0.12 \mathrm{~g} \cdot \mathrm{cm}^{-3}\left(S W E=2.2 \mathrm{~g} \cdot \mathrm{cm}^{-2}\right)$. The fixed parameter values are given in Table 1 . Snow permittivity values $\left(\varepsilon_{1}\right)$ of $1.16-i 5.88 \times$ $10^{-5}$ and $1.24-i 1.26 \times 10^{-4}$ are used in the GPS-IRT $\left(\theta_{t}=-1.7^{\circ}\right)$ and GPS-IR $\left(\theta_{t}=0^{\circ}\right)$ models, respectively. The GPS times for the measurements are $20: 33$ to $21: 38$.

This snow depth difference between the two models indicates that a small tilt angle is having a detrimental effect on retrieving snow depth. In contrast, the GPSIRT method provides better estimates of snow density and SWE than the GPS-IR method. These results show that small tilt angles may have an effect on the retrievals of snow depth, snow density, and SWE. Furthermore, caution must be exercised when attempting

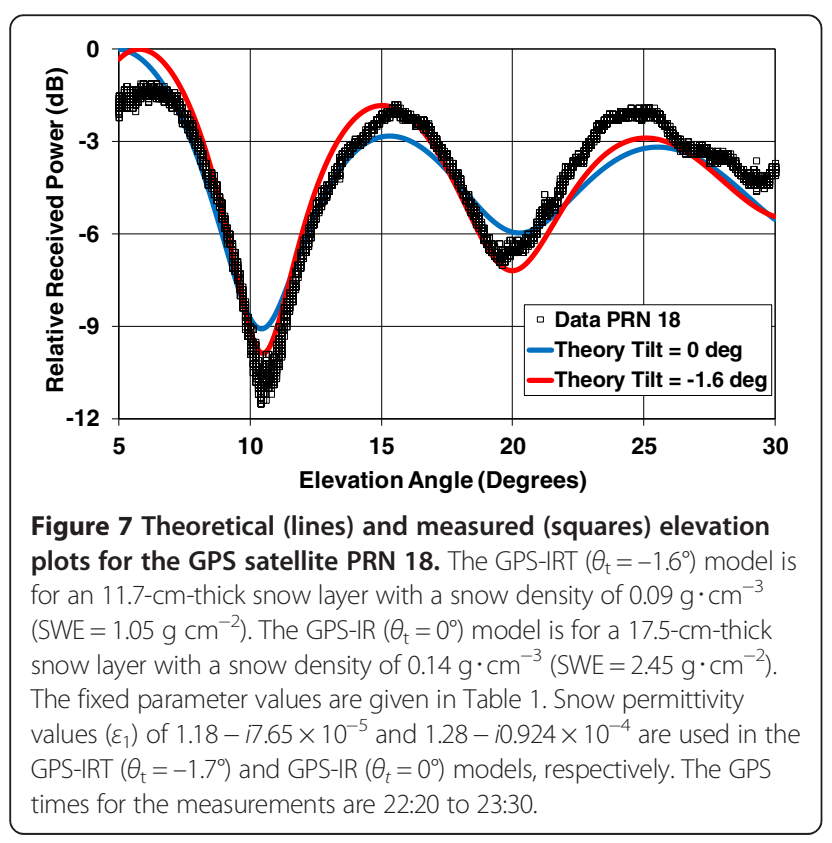

retrievals of snow depth, snow density, and SWE from this simple model. Nevertheless, there may be potential for estimating snow depth, snow density, and SWE using GPS-IRT.

With this in mind, we list several model deficiencies that limit the accuracy of retrieving the snow parameters. First, although the approximation of snow by a planar homogenous layer (with respect to a slightly tilted ground) is reasonable, the approximation of prairie grass by a similar homogeneous planar layer (with respect to a slightly tilted ground) is questionable. Second, approximating the frozen soil as a uniform medium with a constant dielectric permittivity is also questionable. A more realistic frozen-soil model requires a soil dielectric permittivity dependence with depth, and a relationship between the soil dielectric permittivity and soil moisture, as well as soil material composition [22,28,29]. Third, the approximation of a slightly tilted, flat ground surface is questionable since the actual ground surface topography is more complicated than this. The true ground surface topography affects the reflected signals, which, in turn, affects the retrievals of snow depth and density [12]. Therefore, the ground surface topography should be measured and modeled before the satellites will be covered with snow. By using this modeled ground surface topography in the theoretical model, more accurate retrievals of snow depth and density may be possible.

\section{Conclusions}

We investigated a nonlinear least squares fitting technique for inferring snow depth and density for a snow- 
Table 3 Inferred values of snow depth, snow density, SWE, and SE using the GPS-IRT (nonzero ground tilt) method

\begin{tabular}{lcccc}
\hline Method & Snow depth $(\mathbf{c m})$ & Snow density $\left(\mathbf{g} \cdot \mathbf{c m}^{-\mathbf{3}}\right)$ & SWE $\left(\mathbf{g} \cdot \mathbf{c m}^{-\mathbf{2}}\right)$ & SE $(\mathbf{d B})$ \\
\hline GPS-IRT PRN 15 & $13.0(18.3)$ & $0.08(0.12)$ & $1.04(2.20)$ & $0.377(0.642)$ \\
GPS-IRT PRN 18 & $11.7(17.5)$ & $0.09(0.14)$ & $1.05(2.45)$ & $0.760(0.798)$ \\
GPS-IRT AVG & $12.4(17.9)$ & $0.085(0.13)$ & $1.05(2.33)$ & $0.573(0.721)$ \\
In situ & $17.6 \pm 1.5$ & $0.08 \pm 0.02$ & $1.40 \pm 0.36$ & \\
\hline
\end{tabular}

The inferred values using the GPS-IR (zero ground tilt) method [17] are shown in parenthesis. The arithmetical average (AVG) inferred values are also shown. Each in situ range value consists of 11 measurements.

covered prairie grass field using GPS-IRT during a 1-day experiment. The product of these two parameters provides an estimate of the SWE, which helps agricultural resource managers in estimating the amount of moisture for crops when the snow melts into the soil. In addition, SWE estimates are extremely important for hydrological studies in seasonal snow-covered regions because it represents the amount of water potentially available for runoff.

A QNA produced an average inferred snow depth $(12.4 \mathrm{~cm})$, from two satellite tracks, that underestimates the in situ measurements $(17.6 \mathrm{~cm} \pm 1.5 \mathrm{~cm})$. However, the average inferred snow density $\left(0.085 \mathrm{~g} \cdot \mathrm{cm}^{-3}\right)$, from two satellite tracks, is within the in situ range $\left(0.08 \mathrm{~g} \cdot \mathrm{cm}^{-3} \pm 0.02 \mathrm{~g} \cdot \mathrm{cm}^{-3}\right)$. Consequently, the average inferred SWE $\left(1.05 \mathrm{~g} \cdot \mathrm{cm}^{-2}\right)$, from two satellite tracks, is within the in situ calculation range $\left(1.38 \mathrm{~g} \cdot \mathrm{cm}^{-2} \pm\right.$ $0.36 \mathrm{~g} \cdot \mathrm{cm}^{-2}$ ). These results show that there may be potential for estimating snow depth, snow density, and SWE using GPS-IRT. However, caution must be exercised when attempting retrievals of snow depth, snow density, and SWE from this simple model.

For comparison purposes, the GPS-IRT (nonzero ground tilt) model estimates snow density and SWE better than the GPS-IR (zero ground tilt) model. However, the GPS-IR model did better in estimating snow depth than the GPSIRT model. Snow depth and density retrieval results from these models indicate that terrain slopes may be an important factor in the physical model for retrieving snow depth, snow density, and SWE. Furthermore, these retrieval results also indicate that these simple models may be limited in producing accurate retrievals of snow depth, density, and SWE. Further investigation is needed to quantify the usefulness of these models in estimating snow depth, snow density, and SWE.

Continuing research will explore the feasibility of using this technique to infer SWE for snow layers above different types of vegetation, including no vegetation (bare soil). This will require further measurements for different snow depths and densities in open and mountainous terrains. Also, the received signals from different GPS satellites at a specific site and over an appropriate time period need to be compared and analyzed. In addition, potential biases in the retrieved parameters might be reduced if the receiving antenna's height is increased from $0.5 \mathrm{~m}$ to approximately $2 \mathrm{~m}$ (typical antenna height for snow-sensing GPS stations [12-15]). An increased antenna height will produce more power oscillations at the receiving antenna. Continuing theoretical developments will incorporate the following: more snow layers, surface roughness of snow and frozen soil, realistic ground surface topography, realistic prairie grass and frozen soil compositions, the configuration of a horizontally mounted (zenith-pointing) GPS antenna, and the antenna beam pattern including its antenna phase center.

In conclusion, if the GPS-IRT technique can be used in estimating SWE, then it may be more cost-effective than the current techniques. In particular, it may expand the spatial coverage of SWE measurements that are not currently provided by SNOTEL sites. For example, there are hundreds of geodetic GPS receivers operating in snowy regions in the USA [15]. Therefore, some of these GPS receivers could possibly be used to estimate SWE. Furthermore, low-cost GPS receivers could potentially be placed in agricultural snow-covered areas to estimate SWE for crops.

\section{Competing interests}

The author declares that he has no competing interests.

\section{Acknowledgements}

The author would like to thank Montana State University Billings' (MSUB) Research and Creative Endeavor Grant Committee and Tasneem Khaleel of MSUB for their funding. In addition, the author would like to thank $M$. McBride of MSUB, J. Jacobson (my mother), W. Dotson of Keri Systems, and C. McFarland and T. McFarland (land owners) for their critical involvement in this research. The author would also like to thank the anonymous reviewers for their superb comments and suggestions.

Received: 7 August 2013 Accepted: 15 April 2014

Published: 6 May 2014

\section{References}

1. CA Campbell, BG McConkey, RP Zentner, F Selles, FB Dyck, Benefits of wheat stubble strips for conserving snow in southwestern Saskatchewan. J. Soil Water Conserv. 47(1), 112-115 (1992)

2. HN Hayhoe, RG Pelletier, DR Coote, Estimating snowmelt runoff erosion indices for Canada. J. Soil Water Conserv. 50(2), 174-179 (1995)

3. JF Galantowicz, AW England, Radiobrightness signatures of energy balance processes: melt/freeze cycles in snow and prairie grass covered ground. IEEE IGARSS 1, 596-598 (1994). doi:10.1109/igarss.1994.399194 
4. GL Schaefer, RF Paetzold, SNOTEL (SNOwpack TELemetry) and SCAN (Soil Climate Analysis Network), (2000). ftp://ftp.wcc.nrcs.usda.gov/ downloads/factpub/soils/SNOTEL-SCAN.pdf. Accessed 5 June 2013

5. MC Serreze, MP Clark, RL Armstrong, DA McGinnis, RS Pulwarty, Characteristics of the western United States snowpack from snowpack telemetry (SNOTEL) data. Water Resour. Res. 35(7), 2145-2160 (1999). doi: 10.1029/1999wr900090

6. NP Molotch, RC Bales, SNOTEL representatives in the Rio Grande headwaters on the basis of physiographics and remotely sensed snow cover persistence. Hydrol. Process 20, 723-739 (2006). doi:10.1002/hyp.6128

7. S Jin, GP Feng, S Gleason, Remote sensing using GNSS signals: current status and future directions. Adv. Space Res. 47(10), 1645-1653 (2011). doi: 10.1016/j.asr.2011.01.036

8. E Cardellach, F Fabra, O Nogues-Correig, S Oliveras, S Ribó, A Rius, GNSS-R ground-based and airborne campaigns for ocean, land, ice, and snow techniques: application to the GOLD-RTR data sets. Radio Sci 46, RSOC04 (2011). doi:10.1029/2011rs004683

9. S Jin, A Komjathy, GNSS reflectometry and remote sensing: new objectives and results. Adv. Space Res. 46(2), 111-117 (2010). doi: 10.1016/j. asr.2010.01.014

10. S Gleason, D Gebre-Egziabher, GNSS Applications and Methods (Artech House, Norwood, 2009)

11. S Gleason, S Lowe, V Zavorotny, Remote Sensing Using Bistatic GNSS Reflections in GNSS Applications and Methods (Artech House, Norwood, 2009)

12. KM Larson, FG Nievinski, GPS snow sensing: results from the EarthScope plate boundary observatory. GPS Solutions 17, 41-52 (2012). doi:10.1007/ s10291-012-0259-7

13. N Rodriguez-Alvarez, A Aguasca, E Valencia, X Bosch-Lluis, A Camps, I Ramos-Perez, H Park, M Vall-llossera, Snow thickness monitoring using GNSS measurements. IEEE Geosci. Remote Sens. Lett. 9(6), 1109-1113 (2012). doi: 10.1109/lgrs.2012.2190379

14. E Gutmann, KM Larson, M Williams, FG Nievinski, V Zavorotny, Snow measurement by GPS interferometric reflectometry: an evaluation at Niwot Ridge. Colorado. Hydrol Process 26, 2951-2961 (2011). doi: 10.1002/hyp.8329

15. KM Larson, E Gutmann, V Zavorotny, J Braun, M Williams, F Nievinski, Can we measure snow depth with GPS receivers? Geophys. Res. Lett. 36, L17502 (2009). doi:10.1029/2009gl039430

16. MD Jacobson, Dielectric-covered ground reflectors in GPS multipath reception-theory and measurement. IEEE Geosci. Remote Sens. Lett. 5(3), 396-399 (2008). doi: 10.1109/lgrs.2008.917130

17. MD Jacobson, Snow water equivalent estimation for a snow-covered prairie grass field by GPS interferometric reflectometry. Position 3(3), 31-41 (2012). doi: 10.4236/pos.2012.33005

18. MD Jacobson, Inferring snow water equivalent for a snow-covered ground reflector using GPS multipath signals. Remote Sens. 2(10), 2426-2441 (2010). doi: 10.3390/rs2102426

19. WL Stutzman, Polarization in Electromagnetic Systems (Norwood, Artech House, 1993)

20. P Beckman, A Spizzichino, The Scattering of Electromagnetic Waves from Rough Surfaces (Artech House, Norwood, 1987)

21. KM Larson, J Braun, E Small, V Zavorotny, E Gutmann, A Bilich, GPS multipath and its relation to near-surface soil moisture content. IEEE J-Stars 3(2010), 91-99 (2010). doi: 10.1109/JSTARS.2009.2033612

22. V Zavorotny, KM Larson, J Braun, EE Small, E Gutmann, A Bilich, A physical model for GPS multipath caused by land reflections: toward bare soil moisture retrievals. IEEE J. Sel. Topics Appl. Earth Obs. Remote Sens. 3(1), 100-110 (2010). doi: 10.1109/jstars.2009.2033608

23. FT Ulaby, RK Moore, A.K. Fung, Microwave Remote Sensing, Active and Passive, vol. 2 (Norwood, Artech House, 1986)

24. FT Ulaby, RK Moore, AK Fung, Microwave Remote Sensing, Active and Passive, vol. 3 (Norwood, Artech House, 1986)

25. D Herceg, N Krejic, Z Luzanin, Quasi-Newton's method with correction. Novi Sad J. Math. 26(1), 115-127 (1996)

26. JM Martinez, A family of quasi-Newton methods for nonlinear equations with direct secant updates of matrix factorizations. SIAM J. Numer. Anal. 27, 1034-1049 (1990). doi: 10.1137/0727061

27. N Rodriguez-Alvarez, A Camps, M Vall-llossera, X Bosch-Lluis, A Monerris, I Ramos-Perez, E. Valencia, J.F. Marchan-Hernandez, J. Martinez-Fernandez, G Baroncini-Turricchia, C Pérez-Gutiérrez, N Sánchez, Land geophysical parameters retrieval using the interference pattern GNSS-R technique. IEEE Trans. Geosci. Remote Sens. 49(1), 71-84 (2011). doi: 10.1109/tgrs.2010.2049023

28. CC Chew, EE Small, KM Larson, VU Zavorotny, Effects of near-surface soil moisture on GPS SNR data: development of a retrieval algorithm for soil moisture. IEEE Trans. Geosci. Remote Sens. 52(1), 537-543 (2014). doi: 10.1109/tgrs.2013.22422332

29. VL Mironov, RD DeRoo, IV Savin, Temperature-dependable microwave dielectric model for an Arctic soil. IEEE Trans. Geosci. Remote Sens 48(6), 2544-2556 (2010). doi:10.1109/tgrs.2010.2040034

doi:10.1186/1687-6180-2014-61

Cite this article as: Jacobson: Estimating snow water equivalent for a slightly tilted snow-covered prairie grass field by GPS interferometric reflectometry. EURASIP Journal on Advances in Signal Processing 2014 2014:61.

\section{Submit your manuscript to a SpringerOpen ${ }^{\odot}$ journal and benefit from:}

- Convenient online submission

- Rigorous peer review

- Immediate publication on acceptance

- Open access: articles freely available online

- High visibility within the field

- Retaining the copyright to your article

Submit your next manuscript at $\gg$ springeropen.com 